\title{
ACA and the Direction of U.S. Healthcare
}

\author{
Gilbert Berdine MD
}

There are three quotes that will probably be associated with ACA forever. The first quote was by President Obama when he "sold" ACA to the public: "If you like your health care plan, you can keep it." This statement was given the Lie of the Year award by politifact.com. ${ }^{1}$ Cancellation notices went out to approximately 4 million Americans who, apparently, liked their health care plans. The problems were mainly due to the ACA requirement that pre-existing conditions be treated as insurable risks. ${ }^{2}$

ACA defenders claimed that Obama was misunderstood, or that this was an unintended consequence of good intentions. Along came Dr. Jonathan Gruber who became infamous for a few brief moments of candor and clarity about ACA. ${ }^{3}$ Gruber's most revealing quote was not his notorious statement regarding the stupidity of the American voter. Rather, Gruber admitted that increasing premiums to healthy people were a feature of ACA rather than a bug. As Gruber candidly admitted, "If you had a law which said healthy people are going to pay in -- if you made it explicit that healthy people pay in and sick people get money, it would not have passed, OK?" The end of passing ACA justified the means of lying about ACA. As noted in my previous article ${ }^{2}$, ACA was structured as a subsidy for poor health and subsidies always increase costs.

Gruber's "call it the stupidity of the American voter" comment will be forever linked with ACA. Stupidity is probably not the proper term - ambivalence to lies and deception would be more accurate. This final quote tells us much about the future direction of

Corresponding author: Gilbert Berdine MD Contact Information: Gilbert.Berdine@ttuhsc.edu DOI: 10.12746/swrccc 2015.0310.136
U.S. Healthcare. We need to ignore what politicians say and pay attention to what they do. The remaining discussion will examine the finances of U.S. Healthcare and what options will likely be pursued to control costs.

The goals of ACA were to increase the number of insured Americans and reduce the cost of healthcare. In my previous article, I explained that the subsidy nature of ACA would ensure the first goal while make the second goal an impossibility. ${ }^{2}$ Rather than discuss exaggerated claims from either the right or left side of the political spectrum, let us look at predictions by actuaries at the Congressional Budget Office. $^{4}$

\section{Figure 1}

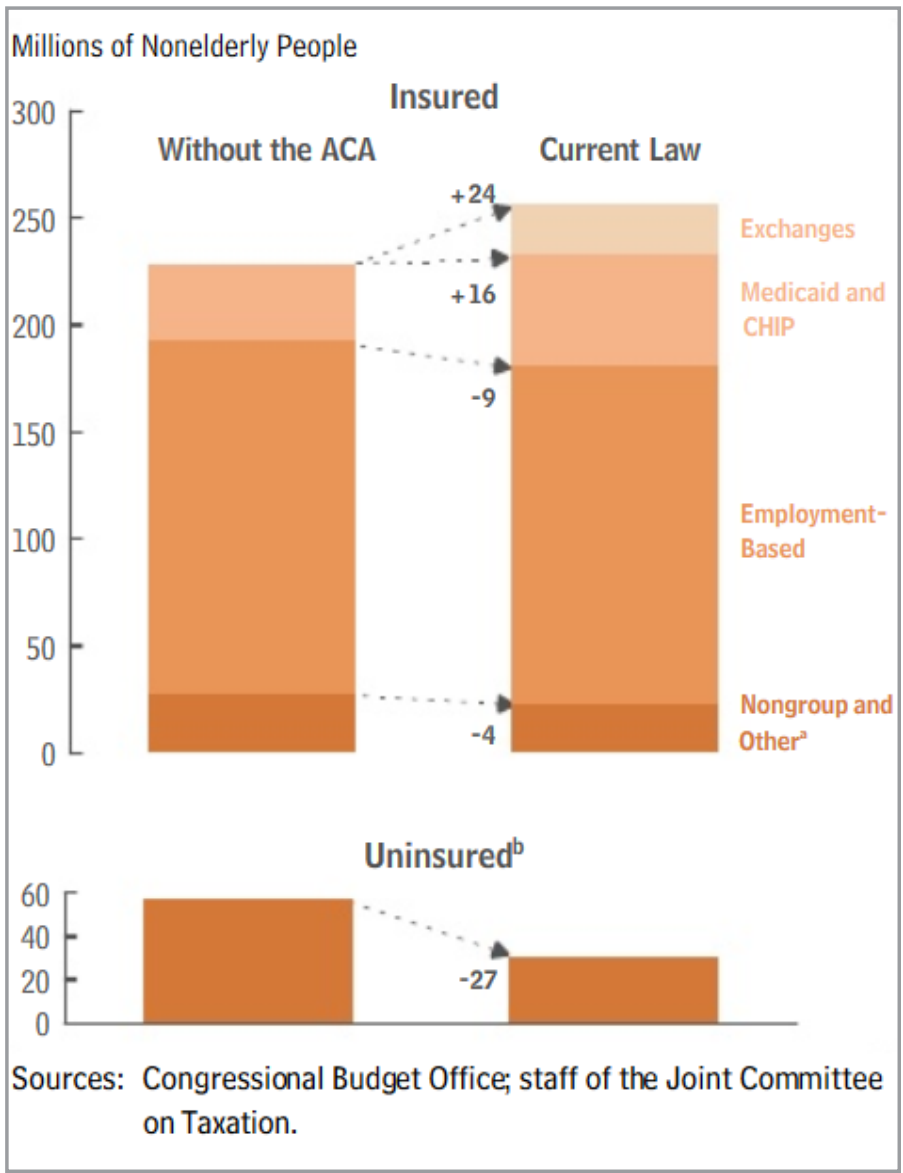


As can be seen from Figure 1, which is taken from the CBO 2015 Outlook on ACA, it is estimated that 27 million more Americans will have some form of insurance due to ACA. ACA must be considered successful on its goal of decreasing the pool of uninsured. Twenty four million are expected to purchase insurance through the ACA exchanges and 16 million are expected to receive ACA benefits through expansion of Medicaid. Not all of these 40 million are happy, however, as nine million are expected to lose employment based health insurance and another four million are expected to lose or forego private health insurance.

Let us examine the current state of Medicare finances. Medicaid has similar problems due to the subsidies for poor health.

\section{Table II.B1. - Medicare Data for Calendar Year 2013}

\begin{tabular}{|c|c|c|c|c|}
\hline & \multirow[b]{2}{*}{$\mathrm{HI}$ or Part A } & \multicolumn{2}{|c|}{ SMI } & \multirow[b]{2}{*}{ Total } \\
\hline & & Part B & Part D & \\
\hline Assets at end of 2012 (billions) & $\$ 220.4$ & $\$ 66.2$ & $\$ 1.0$ & $\$ 287.6$ \\
\hline Total income & $\$ 251.1$ & $\$ 255.0$ & $\$ 69.7$ & $\$ 575.8$ \\
\hline Payroll taxes & 220.8 & - & - & 220.8 \\
\hline Interest & 9.3 & 2.4 & 0.0 & 11.7 \\
\hline Taxation of benefits & 14.3 & - & - & 14.3 \\
\hline Premiums & 3.4 & 63.1 & 9.9 & 76.4 \\
\hline General revenue & 0.9 & 185.8 & 51.0 & 237.7 \\
\hline Transfers from States & - & - & 8.8 & 8.8 \\
\hline Other & 2.4 & 3.7 & - & 6.1 \\
\hline Total expenditures & $\$ 266.2$ & $\$ 247.1$ & $\$ 69.7$ & $\$ 582.9$ \\
\hline Benefits & 261.9 & 243.8 & 69.3 & 575.0 \\
\hline Hospital & 136.8 & 41.8 & - & 178.6 \\
\hline Skilled nursing facility & 28.4 & - & - & 28.4 \\
\hline Home health care & 6.8 & 11.5 & - & 18.4 \\
\hline Physician fee schedule services & - & 68.6 & - & 68.6 \\
\hline Private health plans (Part C) & 73.2 & 72.7 & - & 145.9 \\
\hline Prescription drugs & - & - & 69.3 & 69.3 \\
\hline Other & 16.7 & 49.2 & - & 65.8 \\
\hline Administrative expenses & $\$ 4.3$ & $\$ 3.3$ & $\$ 0.4$ & $\$ 7.9$ \\
\hline Net change in assets & $-\$ 15.0$ & $\$ 7.9$ & $-\$ 0.0$ & $-\$ 7.1$ \\
\hline Assets at end of 2013 & $\$ 205.4$ & $\$ 74.1$ & $\$ 1.0$ & $\$ 280.5$ \\
\hline \multicolumn{5}{|l|}{ Enrollment (millions) } \\
\hline Aged & 43.1 & 40.0 & $\mathrm{n} / \mathrm{a}$ & 43.5 \\
\hline Disabled & 8.8 & 7.9 & $\mathrm{n} / \mathrm{a}$ & 8.8 \\
\hline Total & 51.9 & 47.9 & 39.1 & 52.3 \\
\hline Average benefit per enrollee & $\$ 5,045$ & $\$ 5,092$ & $\$ 1,773$ & $\$ 11,910$ \\
\hline
\end{tabular}

Notes. 1. Totals do not necessarily equal the sums of rounded components.

2. n/a indicates data are not available. 
This summary table from the Trustees Report on Medicare $2014^{5}$ is where most of the headline discussions come from, but its accounting methods hide serious structural problems in the financing of U.S. Healthcare. The headline figure from this table is the $\$ 7.1$ billion loss in the total "assets" at the end of 2013, but this figure is very small compared to financing gimmicks. Of note is that Part A, the Hospital Insurance Fund, has been self-financing for much of its history, but that status has changed. Part A has few financing gimmicks and expenditures are now exceeding income. The largest portion of Part A income is the $\$ 220.8$ billion in payroll taxes. This represents actual income to the Medicare system from the taxpaying public. The $\$ 9.3$ billion in "interest" is an accounting gimmick. Medicare maintains a fiction of a "trust fund" which pays interest. In reality, there are no real investments or actual income - the "interest" is merely a ledger item in the long list of expenditures from General Revenue.

The accounting problems become more apparent with examination of Part B and Part D. Part B covers doctors' fees and outpatient expenditures. Part $D$ is the prescription drug benefit. Payroll taxes are not applied to Parts B and D. There are premiums of $\$ 63.1$ billion, which represent real income from beneficiaries, against $\$ 247.1$ billion in expenditures. Part B shows a surplus because of a huge transfer of $\$ 185.8$ billion from General Revenue. This accounting gimmick is like paying your left hand from money in your right hand and calling it an investment. Part $\mathrm{D}$ has actual premiums of $\$ 9.9$ billion against expenditures of $\$ 69.7$ billion. These accounting gimmicks would not be an issue if General Revenue were in surplus, but General Revenue runs perpetual deficits with no end in sight.

\section{Figure 2}

Overview

Figure II.D2.-Medicare Sources of Non-Interest Income and Expenditures as a Percentage of the Gross Domestic Product

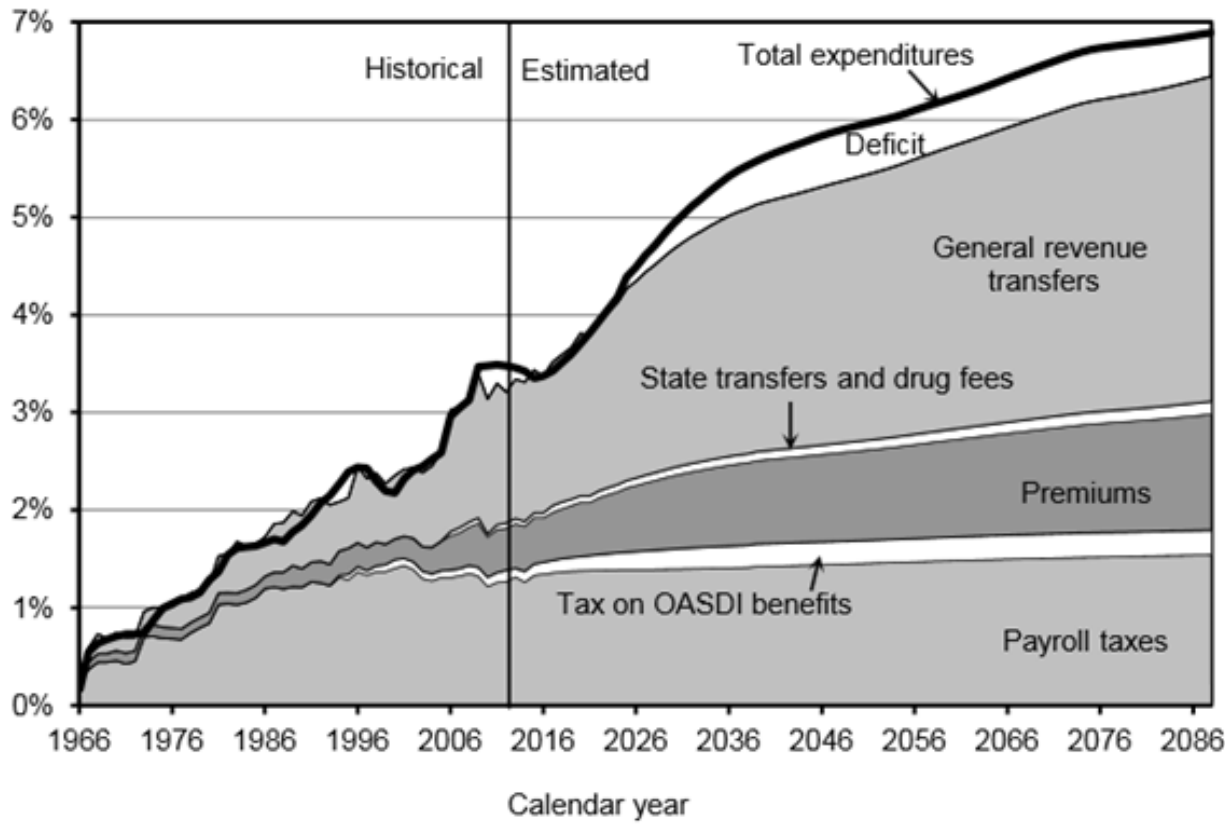


Figure 2 is taken from the Trustees' Report. ${ }^{5}$ This figure makes the above discussion more clear and reveals the true direction of U.S. Healthcare policy. The wedge representing transfers from General Revenue have grown from a negligible contribution in 1966 to the largest part of the pie in present day with projected growth in nominal terms, fraction of the Medicare budget terms, and percentage of GDP terms. This is clearly unsustainable.

Every year the Trustees recommend that reimbursements to physicians be cut by $25-33 \%$ across the board. Every year Congress rescinds this cut. Regulatory burdens both within ACA and prior to ACA represent a non-transparent means of achieving cost cutting ends. This is where Dr. Gruber's quotes become important, because there are many in high positions who "would rather have the law than not."

One example is pay for performance. Who could be against pay for performance? How is performance defined? Performance is not defined by any objective measure of people getting well or good decisions against bad decisions; performance is capriciously and arbitrarily defined as anyone below a certain percentile of performance. Since $1 / 2$ the providers will always be in the bottom half, regardless of how well they perform, Pay for Performance achieves a significant decrease in re-imbursement without the transparency issues of an across the board cut.

A significant impact of ACA is to make the U.S. government the insurer of more and more people. By achieving a monopoly status, the U.S. government can get away with price controls, long queues, and declining reimbursement. Both consumers and providers will have less and less ability to opt out. Physicians have traditionally served their patients, but when the government is the source of payment, physicians will increasingly serve the government rather than the patient.

Author Affiliation: Dr. Gilbert Berdine is a pulmonary physician in the Department of Internal Medicine, TTUHSC.

Published electronically: 4/15/2015

\section{References}

1. http://www.politifact.com/truth-o-meter/article/2013/

$\mathrm{dec} / 12 /$ lie-year-if-you-like-your-health-care-plan-keep-it/

2. http://www.pulmonarychronicles.com/ojs/

index.php?journal=pulmonarychronicles\&page $=$ article\&op $=$ view \& path $\% 5 \mathrm{~B} \% 5 \mathrm{D}=143$

3. http://www.cnn.com/2014/11/14/politics/

obamacare-voters-stupid-explainer/index.html

4. http://www.scribd.com/doc/253801993/CBO-January-

2015-Outlook-on-Obamacare

5. http://www.cms.gov/Research-Statistics-Data-and-Systems/Statistics-Trends-and-Reports/ReportsTrustFunds/downloads/tr2014.pdf 